\title{
Determination of Phytochemical Contents and Biological Activities from the Fruits of Elaeagnus multiflora
}

\author{
Jin Hwan Lee ${ }^{1}$, Weon Taek $\mathrm{Seo}^{2}$, and Kye Man $\mathrm{Cho}^{2 \dagger}$ \\ ${ }^{1}$ Department of Monitoring and Analysis, NAKDONG River Basin Environmental Office, \\ Ministry of Environment, Gyeongnam 641-722, Korea \\ ${ }^{2}$ Department of Food Science, Gyeongnam National University of Science and Technology, Gyeongnam 660-758, Korea
}

\begin{abstract}
The purpose of this study was to investigate the phytochemical contents and biological activities, including a-glucosidase inhibitory activity and antioxidant activity, from the fruits of Elaeagnus multiflora using different solvent systems. The $50 \%$ ethanol extract of this species showed the most potent $\alpha$-glucosidase inibitory activity $(88.5 \%)$ at a concentration of $1 \mathrm{mg} / \mathrm{mL}$. Moreover, this extract also displayed the strongest antioxidant activity in each assay, showing 96.3\% in DPPH scavenging activity, 98.2\% in ABTS scavenging activity, and $2.5 \%$ in reducing power. The highest total phytochemical contents, including flavan-3-ols, phenolic acids, and flavonoids, were observed in the $50 \%$ ethanol extract. Interestingly, flavan-3-ols $(3.150 \mathrm{mg} / \mathrm{g})$ were detected at a significantly higher total content than those of phenolic acids $(0.380 \mathrm{mg} / \mathrm{g}$ ) and flavonoids (not detected). Additionally, the contents of individual phytochemicals showed remarkable differences, especially the epicatechin gallate (2.008 $\mathrm{mg} / \mathrm{g}$ ) and gallic acid $(0.099 \mathrm{mg} / \mathrm{g})$, which were the predominant constituents of each phytochemical type. Therefore, our results suggest that the $\mathbf{5 0 \%}$ ethanol extract of $E$. multiflora fruits has strong biological activities, which are correlated with high phytochemical contents.
\end{abstract}

Key words: Elaeagnus multiflora, fruits, phytochemical, antioxidant, $\alpha$-glucosidase, $50 \%$ ethanol extract

\section{INTRODUCTION}

Phytochemicals are secondary metabolites widely distributed in edible plants, such as crops, fruits, and vegetables (1-3). They possess various beneficial effects, including antitumor, anticancer, antioxidant, anti-inflammatory, anti-atherosclerotic, and anti-diabetic (3-6). In particular, these components are of great interest in the food industry because of their nutritional values (7). Antioxidants have been attributed to inhibit or delay the oxidation of other molecules by inhibiting the initiation and propagation of oxidizing chain reactions. This inhibition helps to maintain the quality of many food products (8). Antioxidants are also a great interest for their pharmacological effects, because the occurrence of oxidation in living organisms is known to cause damage to proteins, lipids, and DNA, resulting in cancer, heart disease, and accelerated aging $(9,10)$. $\alpha$-Glucosidase (EC 3.2.1.20) is an exo-acting carbohydrase, catalyzing release of $\alpha$-D-glucopyranose from the non-reducing ends of various substances (11). Inhibitors of $\alpha$-glucosidase can be used in the treatment of many diseases, such as diabetes, cancer, and HIV (12-14); thus, screening for $\alpha$-glucosidase inhibitors derived from natural plants has become increasingly popular. In our continuing search for biological activities from edible plants, we found that the ethanol extract of Elaeagnus multiflora fruits showed potent $\alpha$-glucosidase inhibitory activity and radical scavenging activity.

E. multiflora is renowned as a phytosterol-rich plant which has been used in traditional Chinese medicine (15). This species belongs to the family of Elaeagnaceae, the fruits, leaves, and roots of which have been used to treat cough, diarrhea, itching, and foul sores for a long time (16). In particular, numerous studies demonstrated that the extracts of E. multiflora have received unprecedented attention due to their pharmacological properties such as anticancer and antioxidant activities $(17,18)$. It is well established that the fruits of E. multiflora contains plentiful carotenoids and that the leaves have high sugar, fatty acid, and phytosterol contents (16). Although previous studies have emphasized the roles of the constituents and physiological effects of the fruit (19-21), a phytochemical profile of the fruit has still not been fully characterized. Furthermore, there is still limited information on its biological properties such as $\alpha$ glucosidase inhibition and antioxidant activities. For this reason, we investigated the possibility of the plant as 
a potent source of biological activities as well as basic information on its phytochemcals.

The objectives of this study were to investigate the phytochemical contents, $\alpha$-glucosidase inhibitory and antioxidant activities in the fruit of E. multiflora. Therefore, we evaluated the biological effects, including $\alpha$ glucosidase inhibitory activity, DPPH and ABTS radical scavenging activities, and reducing power, from different solvent extracts of E. multiflora fruits. We also evaluated changes of 18 phytochemical compounds including 7 flavan-3- ols, 9 phenolic acids, and 2 flavonoids, using various ethanol extracts to obtain information on the optimal solvent condition.

\section{MATERIALS AND METHODS}

\section{Plant material}

E. multiflora was grown in the experimental field of the Geoje Agricultural Research \& Extension Service, in Geoje, Korea and collected in June 2009. This material was cleaned and separated into two different tissues as seeds and fruits. The fruits were freeze-dried, and then stored at $-10^{\circ} \mathrm{C}$ before analysis.

\section{Reagents}

Analytical grade methanol, water, acetonitrile, and acetic acid were purchased for HPLC analysis from J.T. Baker (Phillipsburg, NJ, USA), $\alpha$-Glucosidase (EC 3.2.1. 20 , Baker's Yeast), $p$-nitrophenyl- $\alpha$-D-glucopyranoside, 2,2-diphenyl-1-picrylhydrazyl (DPPH), 2,2'-azino-bis(3ethylbenzthiazoline-6-sulphonic acid) (ABTS), and 6-hydroxy-2,5,7,8-tetramethylchroman-2-carboxylic acid (Trolox) were obtained from Sigma-Aldrich (St. Louis, MO, USA). Seven standard flavan-3-ols, including catechin, catechin gallate, epicatechin, epicatechin gallate, gallocatechin gallate, epigallocatechin, and epigallocatechin gallate were purchased from Sigma-Aldrich. Nine standard phenolic acids, including gallic, protocatechuic, tannic, $p$ hydroxybenzoic, vanillic, chlorogenic, caffeic, $p$ - coumaric, and ferulic acids were also purchased from SigmaAldrich. Two standard flavonoids such as rutin, and quercetin were obtained from Merck (Darmstadt, Germany). All other reagents were of analytical grade.

\section{Instruments}

UV spectra were measured on a Beckman DU650 spectrophotometer (Beckman Coulter, Fullerton, CA, USA). HPLC was performed using an Agilent 1200 series (Agilent Co., Forest Hill, Vic, Australia) equipped with a quaternary HPLC pump, a degasser, and an Agilent 1200 series diode array detector (DAD). Flavan3-ols were analyzed on a TSKgel ODS-100Z column $(4.6 \times 250 \mathrm{~mm}, 5 \mu \mathrm{m}$, Tosoh Corp., Tokyo, Japan). Fur- thermore, phenolic acids and flavonoids were analyzed on a XTerra ${ }^{\mathrm{TM}}$ RP C8 column $(4.6 \times 250 \mathrm{~mm}, 5 \mu \mathrm{m}$, Waters Corp., Milford, MA, USA).

\section{Measurement of $\alpha$-glucosidase inhibitory activity}

$\alpha$-Glucosidase (EC. 3.2.1.20) inhibitory activity was calculated using previously described procedures, with some modifications (22). $\alpha$-Glucosidase was determined using the substrate $p$-nitrophenyl- $\alpha$-D-glucopyranoside at the optimum $\mathrm{pH}$. The reaction was stopped by adding $2 \mathrm{M} \mathrm{NaOH}$. The released $p$-nitrophenol was measured spectrophotometrically at $405 \mathrm{~nm}$. The inhibitory effects of the tested samples were expressed as a percentage.

\section{Measurement of DPPH radical scavenging activity}

The DPPH radical scavenging activity of the samples was measured by the method of Blois (23) with a slight modification. Briefly, various concentrations of sample extracts $(0.1 \mathrm{~mL})$ were added to both $0.49 \mathrm{~mL}$ of methanol and $0.39 \mathrm{~mL}$ of a DPPH methanolic solution (1 $\mathrm{mM})$. The mixture was vortexed vigorously and allowed to stand for $30 \mathrm{~min}$ at room temperature in the dark. The absorbance of the mixture was determined using a spectrophotometer at $517 \mathrm{~nm}$. BHT was used as the reference. The scavenging activity was expressed as a percentage using the following formula: DPPH radical scavenging activity $(\%)=(1-$ absorbance of sample / absorbance control $) \times 100$.

\section{Measurement of ABTS radical scavenging activity}

The ABTS radical scavenging activity was based on the ability of different substances to scavenge the ABTS ${ }^{+}$ radical cation in comparison to a standard (Trolox). The $\mathrm{ABTS}^{+}$was dissolved in $\mathrm{EtOH}$ to make a concentration of $7 \mathrm{mM}$. This radical cation was produced by reacting the $\mathrm{ABTS}^{++}$stock solution with $2.45 \mathrm{mM}$ potassium persulfate and by leaving the mixture for $10 \sim 14 \mathrm{hr}$ until the reaction was complete and the absorbance was stable. The $\mathrm{ABTS}^{++}$stock solution was diluted in ethanol to an absorbance of 0.70 at $734 \mathrm{~nm}$. After the addition of 0.9 $\mathrm{mL}$ of diluted $\mathrm{ABTS}^{+}$to $0.1 \mathrm{~mL}$ of sample, the absorbance was taken 1 min after the initial mixing (24). This scavenging activity (\%) was expressed as a percentage using the following formula: $\mathrm{ABTS}^{++}$radical scavenging activity $(\%)=[$ absorbance of control - absorbance of sample)/ absorbance of control] $\times 100$.

\section{Measurement of reducing power}

Reducing power was determined according to the method of Oyaizu (25). The sample $(2 \mathrm{~mL})$ was mixed with $1 \mathrm{~mL}$ of phosphate buffer $(0.2 \mathrm{M}$ and $\mathrm{pH} 6.6)$ and $2 \mathrm{~mL}$ of $1 \%$ potassium ferricyanide. After the mixture was incubated at $50^{\circ} \mathrm{C}$ for $20 \mathrm{~min}, 2 \mathrm{~mL}$ of $10 \%$ TCA, $2 \mathrm{~mL}$ of distilled water, and $0.4 \mathrm{~mL} 1 \%$ ferric chloride 
were added, and then the absorbance was measured on a spectrophotometer at $700 \mathrm{~nm}$ (DU650 Beckman Coulter). Vitamin $\mathrm{C}$ was used as positive control.

\section{Calibration curves of the individual standards and sample preparation}

$2 \mathrm{mg}$ of each standard was accurately weighed and dissolved in $50 \% \mathrm{MeOH}$ to obtain stock solution of 1.0 $\mathrm{mg} / \mathrm{mL}$ concentration. The calibration curves for 18 standards were made from the serial dilutions of the samples dissolved in 50\% methanol. The linear range and the equation of linear regression were obtained sequentially at $1.0,2.5,5,10,20,40,60,80$ and $100 \mu \mathrm{g} / \mathrm{mL}$. Mean areas $(n=3)$ generated from the standard solution were plotted against concentration to establish the calibration equation. A high linearity of $r^{2}>0.998$ was obtained for each calibration curve. The pulverized sample $(1 \mathrm{~g})$ was extracted with $20 \mathrm{~mL}$ solvent in a shaking incubator at $25^{\circ} \mathrm{C}$ for $12 \mathrm{hr}$. The extract was centrifuged at $3000 \times \mathrm{g}$ for $3 \mathrm{~min}$, filtered through a $0.45 \mu \mathrm{m}$ syringe filter (Whatman Inc., Maidstone, UK), and transferred into a vial. All extracts were stored in a sealed container at $4^{\circ} \mathrm{C}$ prior to HPLC analysis.

\section{HPLC analysis}

The quantification of the relative abundance of the flavan-3-ols within the crude extract was carried out using HPLC analysis. The initial mobile phase consisted of $20 \%$ solvent B (methanol) in solvent $\mathrm{A}\left(10 \mathrm{mM} \mathrm{KH}_{2} \mathrm{PO}_{4}\right)$. This was linearly increased to $60 \%$ solvent $\mathrm{B}$ over a period of $30 \mathrm{~min}$ at a constant flow rate of $1 \mathrm{~mL} / \mathrm{min}$. The column was then held at $80 \%$ solvent B for $10 \mathrm{~min}$. The extract $(20 \mu \mathrm{L})$ of sample was injected onto the column and the absorbance was measured at $270 \mathrm{~nm}$. The column temperature was set to $30^{\circ} \mathrm{C}$. To phenolic acid and flavonoid analyses, sample extract $(20 \mu \mathrm{L})$ was injected onto an analytical reverse phase $\mathrm{C}_{18}$ column by HPLC. The mobile phase was composed of $0.5 \%$ acetic acid in water (solution A) and methanol (solution B). The gradient program was as follows: $0 \% \mathrm{~B}$ to $10 \%$ B (5 min), $10 \%$ B to $20 \%$ B (10 min), $20 \%$ B to $30 \%$ B (10 min), $30 \%$ B to $40 \%$ B (20 min), $40 \%$ B to $60 \%$ B (10 min), $60 \%$ B to $80 \%$ B (5 min), $80 \%$ B to $100 \%$ $\mathrm{B}(5 \mathrm{~min})$, and then maintained for $10 \mathrm{~min}$ before returning to the initial conditions. The column temperature was set to $30^{\circ} \mathrm{C}$ and the flow rate was $1.0 \mathrm{~mL} / \mathrm{min}$. Total retention time was $60 \mathrm{~min}$ and the detection was made at $280 \mathrm{~nm}$.

\section{Statistical analysis}

Data were expressed as means \pm SD (standard deviation) of three replicates. The results were subject to analysis of variance using Sigma plot to analyse the difference.

\section{RESULTS AND DISCUSSION}

\section{$\alpha$-Glucosidase inhibitory activity of $E$. multiflora fruits}

The extracts of E. multiflora fruits were obtained using five different solvents: hexane, ethylacetate, ethanol, butanol, and methanol. Their activities were estimated by the percentage inhibition through the extract of each solvent. Among them, the ethanol extract displayed the highest inhibitory activity (75.5\%) at a concentration of $1 \mathrm{mg} / \mathrm{mL}$, followed by methanol (70.4\%), butanol (68.7 $\%$ ), ethylacetate $(51.5 \%)$, and hexane $(16.2 \%)$ extracts. To obtain the best extraction condition of ethanol, the extracts of this species were obtained using solvents with $0,25 \%, 50 \%$, and $75 \%$ of water. As shown in Fig. 1, the $\alpha$-glucosidase inhibitory activities of two extracts were similar effects. In other words, the $50 \%$ ethanol extract exhibited the highest activity $(88.5 \%)$, followed by the $75 \%$ ethanol extract $(86.5 \%)$, and the $100 \%$ ethanol extract $(75.5 \%)$, whereas the lowest inhibitory activity was detected in the $25 \%$ ethanol extract $(66.2 \%)$. To our knowledge, this study provides the first documentation of this observation. This result suggests that the extract of ethanol-water mixture in E. multiflora fruits has potent $\alpha$-glucosidase inhibitory activity and may be useful as an effective anti-diabetic agent.

\section{Radical scavenging activity of $E$. multiflora fruits}

To measure antioxidant activity of the extract from the fruits of E. multiflora, the DPPH and ABTS radical scavenging methods were used. These two methods are widely used to test the free radical scavenging ability of various samples because of their good reproducibility and easy quality control $(26,27)$. In this study, DPPH and ABTS radical scavenging activities were estimated by the percentage inhibition of radical formation by the sample extract. The DPPH radical scavenging activities of the extract and BHT (positive control) increased with increasing extract concentrations. Among the five differ-

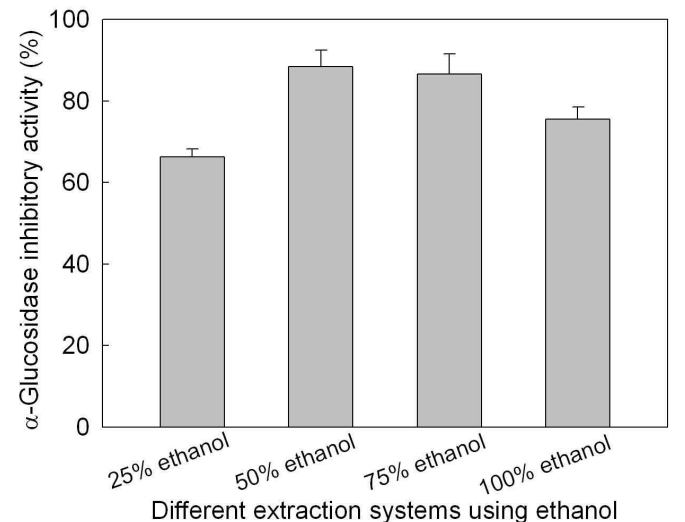

Fig. 1. $\alpha$-Glucosidase inhibitory activity from different ethanol extracts. 
ent extracts, the DPPH radical scavenging ability of the ethanol extract $(78.2 \%)$ was higher than those of the hexane $(25.0 \%)$, ethylacetate $(58.7 \%)$, butanol $(69.5 \%)$, and methanol $(76.6 \%)$ extracts at a concentration of $1 \mathrm{mg} /$ $\mathrm{mL}$. Our result was similar to that of the published data from the leaves of this species (28). However, Kim et al. (17) also reported that the dichloromethane extract of E. multiflora flesh showed the highest DPPH radical scavenging activity. This result suggests that the contents of phytochemicals in E. multiflora may be affected by factors such as environmental stresses, genetics, and agronomic conditions as seen in the results of the previous study (29). In order to evaluate the best effect of the ethanol extraction, the fruit extracts were obtained using solvents with $0,25,50$, and $75 \%$ of water as the ethanol-water mixture extracts of $\alpha$-glucosidase inhibitory activities. Although the four extracts did not display significant differences in their DPPH radical scavenging activity, the $50 \%$ ethanol extract exhibited the highest effect (96.3\%) (Fig. 2A). These results indicate that the $50 \%$ ethanol extract of E. multiflora fruits has potent source of antioxidant agent. In general, it is well established that antioxidant activity of natural plants are attributed to the phenolic compounds (30). Therefore, our result suggests that the $50 \%$ ethanol extract of $E$. multiflora fruits may possess the highest phenolic compound contents, based on our observation of their strong radical scavenging activity.

The scavenging activity of the extract on free radical ABTS generated by potassium persulphate was compared with a standard amount of Trolox (31). The ethanol extract exhibited the highest ABTS radical scavenging activity (78.5\%) at a concentration of $1 \mathrm{mg} / \mathrm{mL}$, followed by the methanol (75.4\%), butanol (68.2\%), ethylacetate $(53.6 \%)$, and hexane $(20.7 \%)$ extracts. This scavenging activity displayed significant differences with each extract similar to that observed with the $\alpha$-glucosi-

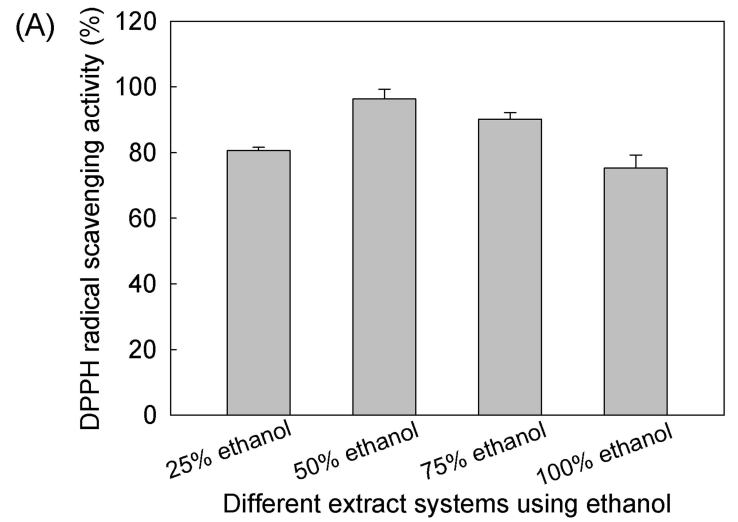

Fig. 2. Antioxidant activities from different ethanol extracts. (A) DPPH radical scavenging activity, (B) ABTS radical scavenging activity. dase inhibitory and DPPH radical scavenging activities. To select the most effective solvent condition, the ABTS radical scavenging activities in the extracts of ethanol and water mixtures $(0,25,50$, and $75 \%)$ were investigated. As illustrated in Fig. 2B, the ABTS radical scavenging activity in each extract did not show strong differences; however, the $50 \%$ ethanol extract had the strongest activity (98.2\%) at a concentration of $1 \mathrm{mg} /$ $\mathrm{mL}$. Again, these results were similar to those observed for DPPH radical scavenging activity as well as $\alpha$-glucosidase inhibitory activity. Moreover, this extract had higher ABTS radical scavenging effect than that of Trolox (positive control) under the same concentration (Fig. 2B). On the basis of the above observations, our results suggest that the extract of the ethanol-water mixture in E. multiflora fruits has potent free radical scavenger activity and may be useful as a good source of natural antioxidants for food and medicinal purposes.

\section{Reducing power of $E$. multiflora fruits}

The ethanol extract also showed the strongest reducing power $(1.26 \%)$ in comparison to the other solvent extracts at $1 \mathrm{mg} / \mathrm{mL}$. This result was similar to those of free radical scavenging and $\alpha$-glucosidase inhibitory activities. The best extraction condition using ethanol exhibited the extract of $50 \%$ water mixture. Thus, this extract may have the ability to react with free radicals to stabilize and terminate radical chain reactions. As a result, the $50 \%$ ethanol extract showed a stronger reducing power $(2.50 \%)$ when compared to other extracts, but vitamin $\mathrm{C}$ (positive control) had the strongest reducing power. The reducing powers at a concentration of $1 \mathrm{mg} /$ $\mathrm{mL}$ were found in the following descending order: vita$\min \mathrm{C}(4.75 \%)>50 \%$ ethanol extract $(2.50 \%)>75 \%$ ethanol extract $(2.28 \%)>25 \%$ ethanol extract $(2.00 \%)>$ $100 \%$ ethanol extract $(1.26 \%)$.

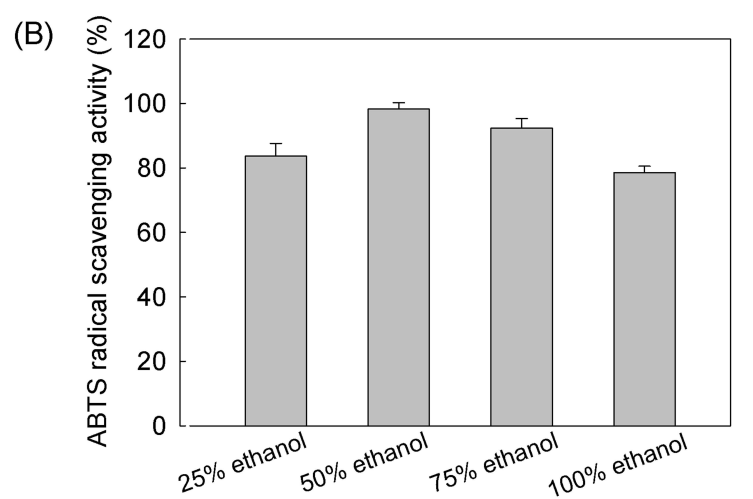

Different extraction systems using ethanol 


\section{Phytochemical contents in $E$. multiflora fruits}

It is well known that the types of phytochemicals extracted from foods, edible sources, and natural plants are strongly dependent on the solvent used for the extraction (32). In this study, the ethanol extract was observed to have predominant antioxidant activity. Based on the above consideration, we evaluated the composition of phytochemicals from the ethanol extract of E. multiflora fruits using HPLC analysis. Furthermore, we investigated changes in the phytochemical contents by different solvent systems to confirm the solvent condition of optimal extraction. Although natural products have many compounds, we selected general phytochemicals to investigate, including 7 flavan-3-ols, 9 phenolic acids, and 2 flavonoids. All standards were identified by their retention times and their contents were calculated by comparing the peak areas of samples. On the basis of individual 7 flavan-3-ols (epigalloactechin (1), catechin (2), epicatechin (3), epigallocatechin gallate (4), gallocatechin gallate (5), epicatechin gallate $(\mathbf{6})$, and catechin gallate (7)) (Fig. 3A), a typical HPLC chromatogram is obtained as illustrated in Fig. 3B.

Their retention times are as follows: (1), $8.4 \mathrm{~min}$; (2), $10.5 \mathrm{~min}$; (3), $14.2 \mathrm{~min}$; (4) $14.8 \mathrm{~min}$; (5), $17.6 \mathrm{~min}$; (6), $21.7 \mathrm{~min}$, and (7) $24.6 \mathrm{~min}$. To quantitatively analyze 7 flavan-3-ols, calibration curves were calculated in the range $1 \sim 100 \mu \mathrm{g} / \mathrm{mL}$ and their equations were $y=15.89 x$ -241.44 (1), $y=4.77 x-59.12$ (2), $y=5.51 x-92.17$ (3), $y=12.60 x+42.13$ (4), $y=18.54 x-67.11 \quad$ (5), $y=2.36 x+$ 49.34 (6), and $y=15.21 x-44.84$ (7). The correlation coefficients were greater than 0.998 , which showed a very nice linearity within the test concentration range. All flavan-3-ols are shown in Table 1. Significant differences were observed between individual and total flavan-3-ol contents in different solvent systems.

Among the four extracts, the $50 \%$ ethanol extract showed the greatest total content $(3.150 \mathrm{mg} / \mathrm{g})$, followed by the $75 \%$ ethanol extract $(2.854 \mathrm{mg} / \mathrm{g})$, and the $25 \%$ ethanol extract $(2.270 \mathrm{mg} / \mathrm{g})$, while the $100 \%$ ethanol extract exhibited the lowest content $(2.010 \mathrm{mg} / \mathrm{g})$. As a result, the flavan-3-ol contents demonstrated significant differences in extract levels according to the amount of water in ethanol. The results of this study demonstrated that the biological effects including $\alpha$-glucosidase inhibitory and antioxidant activities from the fruits of $E$. multiflora significantly depended on the flavan-3-ol contents. Our work was similar to those of the previous studies $(30,33)$. The most predominant flavan-3-ol was epicatechin gallate and its content showed $1.000(25 \%$ ethanol extract, 44\%), 2.008 (50\% ethanol extract, 64\%), 2.038 (75\% ethanol extract, $71 \%)$, and $1.574 \mathrm{mg} / \mathrm{g}(100$ $\%$ ethanol extract, $78 \%$ ), respectively. Notably, the 100<smiles>Oc1cc(O)c2c(c1)O[C@H](c1cc(O)c(O)c(O)c1)[C@H]2O</smiles><smiles>Oc1cc(O)c2c(c1)OC(c1ccc(O)c(O)c1)C(O)C2</smiles><smiles>Cc1cc(O)c(O)cc1C1Oc2cc(O)cc(O)c2CC1O</smiles><smiles>O=C(O[C@@H]1Oc2c(O)cc(O)cc2O[C@@H]1c1cc(O)c(O)c(O)c1)c1cc(O)c(O)c(O)c1</smiles><smiles>O=C(Oc1cc(O)c(O)c(O)c1)c1cc(O)c(O)c(O)c1C1Oc2cc(O)cc(O)c2CC1O</smiles><smiles>Oc1cc(O)c2c(c1)OC(c1ccc(O)c(O)c1)C(OCc1cc(O)c(O)c(O)c1)O2</smiles><smiles>Oc1cc(O)c2c(c1)OC(c1ccc(O)c(O)c1)C(OOc1cc(O)c(O)c(O)c1)O2</smiles>

(B)

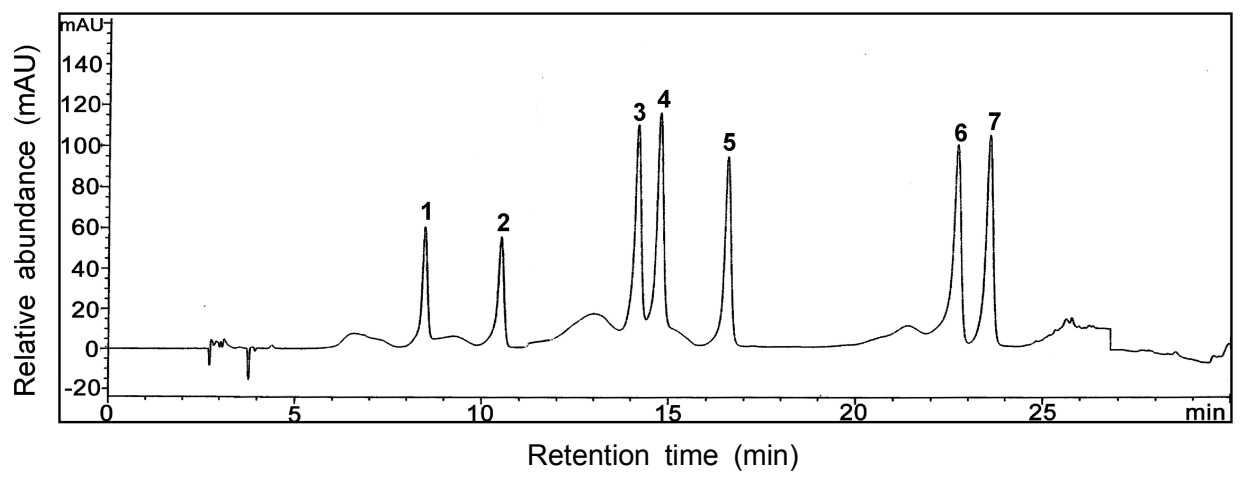

Fig. 3. Chemical structures of flavan-3-ols (A) and HPLC chromatogram containing the standards mixture (B). 1: epigalloactechin, 2: catechin, 3: epicatechin, 4: epigallocatechin gallate, 5: gallocatechin gallate, 6: epicatechin gallate, and 7: catechin gallate. 
Table 1. Contents of 7 flavan-3-ol derivatives using different solvent systems.

\begin{tabular}{lcccc}
\hline \multirow{2}{*}{ Flavan-3-ol derivatives } & \multicolumn{4}{c}{ Flavan-3-ol $(\mathrm{mg} / \mathrm{g})^{1)}$} \\
\cline { 2 - 5 } & $25 \%$ ethanol & $50 \%$ ethanol & $75 \%$ ethanol & $100 \%$ ethanol \\
\hline Epigallocatechin (1) & $0.073 \pm 0.006$ & $0.125 \pm 0.012$ & $0.075 \pm 0.004$ & $0.023 \pm 0.001$ \\
Catechin (2) & $0.769 \pm 0.025$ & $0.676 \pm 0.028$ & $0.419 \pm 0.014$ & $0.090 \pm 0.007$ \\
Epicatechin (3) & $0.266 \pm 0.012$ & $0.180 \pm 0.010$ & $0.149 \pm 0.006$ & $0.079 \pm 0.003$ \\
Epigallocatechin gallate (4) & $0.091 \pm 0.005$ & $0.089 \pm 0.005$ & $0.071 \pm 0.002$ & $0.197 \pm 0.005$ \\
Gallocatechin gallate (5) & $\mathrm{ND}^{2)}$ & $\mathrm{ND}$ & $\mathrm{ND}$ & $\mathrm{ND}$ \\
Epicatechin gallate (6) & $1.000 \pm 0.041$ & $2.008 \pm 0.095$ & $2.038 \pm 0.086$ & $1.574 \pm 0.076$ \\
Catechin gallate (7) & $0.076 \pm 0.005$ & $0.071 \pm 0.002$ & $0.102 \pm 0.004$ & $0.048 \pm 0.001$ \\
\hline
\end{tabular}

${ }^{1)}$ All values are presented as the mean $\pm \mathrm{SD}$ of triplicate determinations. ${ }^{2)} \mathrm{ND}$ : not detected.

$\%$ ethanol extract displayed more than $75 \%$ of total flavan-3-ol content. Among the remaining flavan-3-ols, catechin had the highest content, followed by epicatechin, epigallocatechin gallate, and catechin gallate, while gallocatechin gallate was not detected. Quantification of the 9 phenolic acids [gallic acid (8), protocatechuic acid (9), tannic acid (10), $p$-hydroxylbenzoic acid (11), vanillic acid (12), chlorogenic acid (13), caffeic acid (14), $p$-coumaric acid (15), and ferulic acid (16)] and 2 flavonoids [rutin (17) and quercetin (18)] (Fig. 4A) in the fruits of E. multiflora was also performed by HPLC analysis and their HPLC chromatogram was obtained as shown in Fig. 4B. The retention times were as follows: (8), $7.4 \mathrm{~min}$; (9), $9.9 \mathrm{~min}$; (10), $12.4 \mathrm{~min}$; (11), $12.9 \mathrm{~min}$; (12), $14.3 \mathrm{~min}$; (13), $15.7 \mathrm{~min}$; (14), $16.3 \mathrm{~min}$; (15), 20.7 min; (16), $21.6 \mathrm{~min}$; (17), $35.4 \mathrm{~min}$; and (18), $51.3 \mathrm{~min}$. The concentrations of phenolic acids and flavonoids were determined on the basis of the peak area in the chromatogram as follows: $y=52.44 x+64.50(\mathbf{8}), y=29.59 x$ - 17.54 (9), $y=143.64 x+80.57$ (10), $y=25.19 x+11.94$ (11), $y=33.82 x+11.00$ (12), $y=29.67 x-8.12$ (13), $y=63.34 x-$ 24.52 (14), $y=128.44 x-124.71$ (15), $y=58.54 x-79.55$ (16), $y=13.85 x-2.27$ (17), and $y=27.47 x-30.51$ (18). A high linearity $\left(r^{2}>0.998\right)$ was obtained for each calibration curve.

Phenolic acids and flavonoids are present in a widespread group of edible sources and natural plants that possess varied biological effects, including antioxidant activity (34). Thus, the ethanol extract with the highest antioxidant activity was evaluated. We determined phenolic acid and flavonoid contents by ethanol and water mixtures in order to select the most efficient solvent. These phytochemicals were also identified by comparison with the HPLC retention times of the standards.

(A)
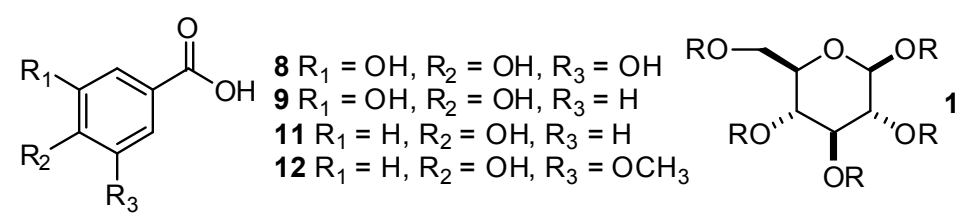

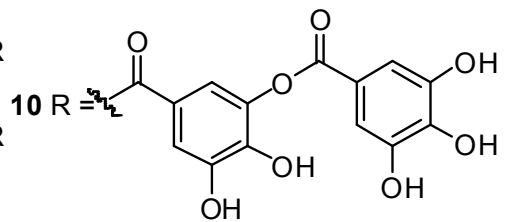<smiles>[R20]OC(=O)/C=C/c1ccc(O)c([R])c1</smiles>

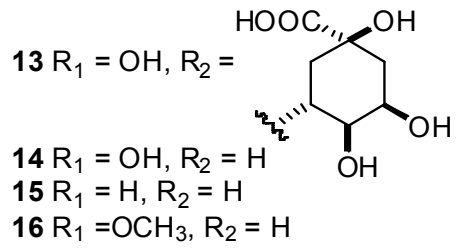<smiles>[R]C1=C([R20])C(c2ccc(O)c(O)c2)Oc2cc(O)cc(O)c2C1=O</smiles>

(B)

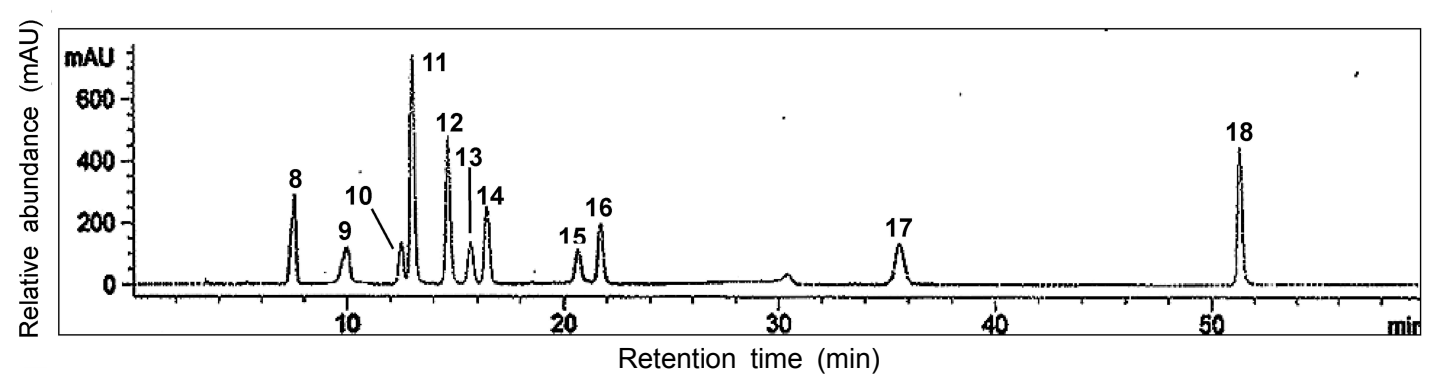

Fig. 4. Chemical structures of phenolic acids and flavonoids (A) and HPLC chromatogram containing the standards mixture (B). 8: gallic acid, 9: protocatechuic acid, 10: tannic acid, 11: p-hydroxylbenzoic acid, 12: vanillic acid, 13: chlorogenic acid, 14: caffeic acid, 15: p-coumaric acid, 16: ferulic acid, 17: rutin, and 18: quercetin. 
Table 2. Contents of 9 phenolic acids and 2 flavonoid derivatives using different solvent systems

\begin{tabular}{lcccc}
\hline Phenolic acid/flavonoid & \multicolumn{4}{c}{ Phenolic acid and flavonoid $(\mathrm{mg} / \mathrm{g})^{1)}$} \\
\cline { 2 - 5 } derivatives & $25 \%$ ethanol & $50 \%$ ethanol & $75 \%$ ethanol & $100 \%$ ethanol \\
\hline Gallic acid (8) & $0.046 \pm 0.003$ & $0.099 \pm 0.005$ & $0.090 \pm 0.004$ & $0.045 \pm 0.002$ \\
Protocatechuic acid (9) & $0.028 \pm 0.003$ & $0.057 \pm 0.003$ & $0.075 \pm 0.003$ & $0.046 \pm 0.001$ \\
Tannic acid (10) & $0.005 \pm 0.000$ & $0.006 \pm 0.000$ & $0.010 \pm 0.001$ & $0.010 \pm 0.001$ \\
$p$-Hydroxylbenzoic acid (11) & $0.036 \pm 0.002$ & $0.043 \pm 0.003$ & $0.035 \pm 0.002$ & $0.027 \pm 0.002$ \\
Vanillic acid (12) & $0.027 \pm 0.002$ & $0.071 \pm 0.005$ & $0.058 \pm 0.002$ & $0.059 \pm 0.003$ \\
Chlorogenic acid (13) & $\mathrm{ND}$ & $\mathrm{ND}$ & $\mathrm{ND}$ & $\mathrm{ND}$ \\
Caffeic acid (14) & $\mathrm{ND}$ & $\mathrm{ND}$ & $\mathrm{ND}$ & $\mathrm{ND}$ \\
$p$-Coumaric acid (15) & $0.079 \pm 0.003$ & $0.087 \pm 0.005$ & $0.049 \pm 0.003$ & $0.028 \pm 0.001$ \\
Ferulic acid (16) & $0.012 \pm 0.001$ & $0.017 \pm 0.001$ & $0.008 \pm 0.001$ & $0.011 \pm 0.001$ \\
Rutin (17) & $\mathrm{ND}$ & $\mathrm{ND}$ & $\mathrm{ND}$ & $\mathrm{ND}$ \\
Quercetin (18) & $\mathrm{ND}$ & $\mathrm{ND}$ & $\mathrm{ND}$ & $\mathrm{ND}$ \\
\hline
\end{tabular}

${ }^{1)}$ All values are presented as the mean $\pm \mathrm{SD}$ of triplicate determinations. ${ }^{2)} \mathrm{ND}$ : not detected.

As illustrated in Table 2, the contents of all compounds in each extract did not display significant differences. However, the $50 \%$ ethanol extract showed the highest content $(0.380 \mathrm{mg} / \mathrm{g})$, while the lowest content was present in the $100 \%$ ethanol extract $(0.225 \mathrm{mg} / \mathrm{g})$. This phenomenon appears similar to the pattern of the flavan-3-ol concentration. The efficiency of the solvents studied for extraction of phenolic acids and flavonoids from E. multiflora fruits presented in the following order: $50 \%$ ethanol extract $(0.380 \mathrm{mg} / \mathrm{g})>75 \%$ ethanol extract $(0.325$ $\mathrm{mg} / \mathrm{g})>25 \%$ ethanol extract $(0.233 \mathrm{mg} / \mathrm{g})>100 \%$ ethanol extract $(0.225 \mathrm{mg} / \mathrm{g})$. Fig. 5 shows the HPLC chromatograms of the highest phytochemical contents, including flavan-3-ol, phenolic acids, and flavonoids from the 50\% ethanol extract of E. multiflora fruits. Furthermore, gallic acid, vanillic acid, and $p$-coumaric acid were major components, whereas chlorogenic acid, rutin, and quercetin
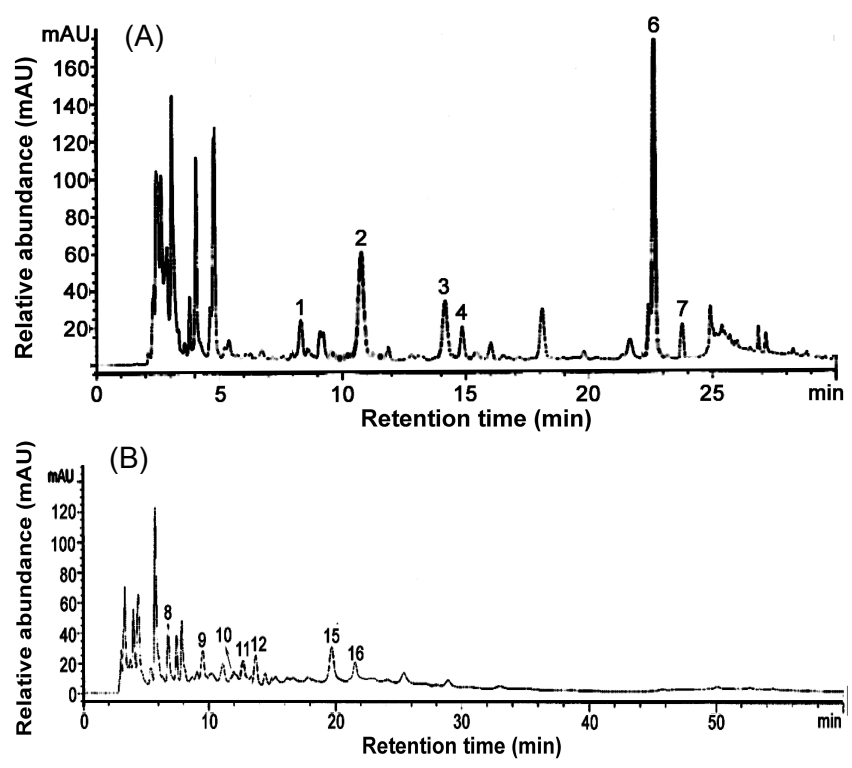

Fig. 5. HPLC chromatograms of the $50 \%$ ethanol extract in E. multiflora fruits. (A) HPLC chromatogram of flavanol-3ols, (B) HPLC chromatogram of phenolic acids and flavonoids. were not detected in all extracts (Table 2). Based on these results, we concluded that the contents of phenolic acid and flavonoid in E. multiflora fruits showed no significant differences in each extract according to the water amounts.

\section{CONCLUSION}

For the first time, this study has documented the biological effects and phytochemical contents of extracts from the fruits of E. multiflora derived with different solvent systems. The $50 \%$ ethanol extract showed the most potent inhibitory activity toward $\alpha$-glucosidase. This extract also displayed the highest antioxidant activities in the DPPH and ABTS, and reducing power analyses. The contents of flavan-3-ols showed significant differences, while phenolic acid and flavonoid contents exhibited slight variations in the extracts of ethanol-water mixture. In addition, the $50 \%$ ethanol extract displayed the highest phytochemical contents, especially epicatechin gallate (7), which exhibited the highest individual concentration of the various extracts. Consequently, our results suggest that the $50 \%$ ethanol extract of E. multiflora fruits may be used as an effective natural source for food and pharmaceuticals, based on its strong biological activities and high phytochemical contents.

\section{ACKNOWLEDGMENT}

This work was supported by the Famer's Technology Development Program of the Rural Development Administration, Republic of Korea.

\section{REFERENCES}

1. Lee JH, Kang NS, Shin SO, Shin SH, Lim SG, Suh DY, Baek IY, Park KY, Ha TJ. 2009. Characterisation of anthocyanins in the black soybean (Glycine $\max$ L.) by HPLC-DAD-ESI/MS analysis. Food Chem 112: 226-231. 
2. Repčák M, Krausová T. 2009. Phenolic glucosides in the course of ligulate flower development in diploid and tetraploid Matricaria chamomilla. Food Chem 116: 19-22.

3. Lee JH, Lee BW, Kim JH, Jeong TS, Kim MJ, Lee WS, Park KH. 2006. LDL-antioxidant pterocarpans from roots of Glycine max (L.) Merr. J Agric Food Chem 54: 20572063.

4. Lee BW, Lee JH, Lee ST, Lee HS, Lee WS, Jeong TS, Park KH. 2005. Antioxidant and cytotoxic activities of xanthones from Cudrania tricuspidata. Bioorg Med Chem Lett 15: 5548-5552.

5. Ko HH, Hung CF, Wang JP, Lin CN. 2008. Antiinflammatory triterpenoids and steroids from Ganoderma lucidum and G. tsugae. Phytochemistry 69: 234-239.

6. Choi SB, Wha JD, Park S. 2004. The insulin sensitizing effect of homoisoflavone-enriched fraction in Liriope platyphylla Wang et Tang via $\mathrm{PI}_{3}$-kinase pathway. Life Sci 75: 2653-2664.

7. Parr AJ, Bolwell GP. 2000. Phenols in plant and in man. The potential for possible nutritional enhancement of this diet by modifying the phenols content or profile. $J \mathrm{Sci}$ Food Agric 80: 985-1012.

8. Javanmardi JC, Locke SE, Vivanco JM. 2003. Antioxidant activity and total phenolic content of Iranian Ocimum accessions. Food Chem 83: 547-550.

9. Breimer LH. 1998. Ionizing radiation-induced mutagenesis. Brit J Cancer 57: 6-18.

10. McCord JM. 2000. The evolution of free radicals and oxidative stress. Am J Med 108: 652-659.

11. Chiba S. 1988. Handbook of amylases and related enzymes. Amylase Research Society of Japan, ed. Pergamon, Oxford, UK. p 104-106.

12. Ducep JB, Kastner PR, Marshall FN, Danzin C. 1991. New potent $\alpha$-glucohydrolase inhibitor MDL 73945 with long duration of action in rats. Diabetes 40: 825-830.

13. Fernandes B, Sagman U, Auger M, Demetrio M, Dennism JW. 1991. $\beta 1-6$ branched oligosaccharides as a marker of tumor progression in human breast and colon neoplasia. Cancer Res 51: 718-723.

14. Ogawa S, Maruyama A, Odagiri T, Yuasa H, Hashimoto H. 2001. Synthesis and biological evaluation of $\alpha$-L-fucosidase inhibitors: 5a-carba- $\alpha$-L-fucopyranosylamine and related compounds. Eur J Org Chem 2001: 967-974.

15. Sakamura F, Suga T. 1987. Changes in chemical components of ripening oleaster fruits. Phytochemistry 26: 24812484.

16. Kim JG. 1984. Illustrated Natural Drugs Encyclopedia. Namsadang, Seoul, Korea. Vol I, p 279.

17. Kim SA, Oh SI, Lee MS. 2007. Antioxidative and cytotoxic effects of solvent fractions from Elaeagnus multiflora. Korean J Food Nutr 20: 134-142.

18. Hong JY, Nam HS, Lee YS, Yoon KY, Kim NW, Shin SR. 2006. Study on the antioxidant activity of extracts from the fruit of Elaeagnus multiflora Thumb. Korean $J$ Food Preserv 13: 413-419.

19. Shin SR, Hong JY, Yoon KY. 2008. Antioxidant properties and total phenolic contents of cherry elaeagnus (Elageagnus multiflora Thunb.) leaf extracts. Food Sci Bio- technol 37: 608-612.

20. Kim NW, Joo EY, Kim SL. 2003. Analysis on the components of the fruit of Elaeagnus multiflora Thumb. Korean $J$ Food Preserv 10: 534-539.

21. Hong JY, Nam HS, Lee YS, Kim NW, Shin SR. 2006. Antioxidant activity of ethanol extracts from fruits of Elaeagnus multiflora Thunb. during maturation. Korean J Food Preserv 13: 643-648.

22. Kato A, Kato N, Kano E, Adachi I, Ikeda K, Yu L, Okamoto T, Banba Y, Ouchi H, Takahata H, Asano N. 2005. Biological properties of D- and L-1-deoxyazasugars. $J$ Med Chem 48: 2036-2044.

23. Blois MA. 1958. Antioxidant determination by the use of a stable free radical. Nature 181: 1199-1200.

24. Fellegrin N, Ke R, Yang M, Rice-Evans C. 1999. Screening of dietary carotenoids and carotenoid-rich fruit extracts for antioxidant activities applying 2,2'-azinobis(3-ethylbenzothiazoline-6-sulfonic acid) radical cation decolorization assay. Method Enzymol 299: 379-389.

25. Oyaizu M. 1986. Studies on products of browning reaction: Antioxidative activities of products of browning reaction prepared from glucosamine. Jap J Nutr 44: 307 315.

26. Sakanaka S, Tachibana Y, Okada Y. 2005. Preparation and antioxidant properties of extracts of Japanese persimmon leaf tea (Kakinohacha). Food Chem 89: 569-575.

27. Brand-Williams W, Cuvelier ME, Berset C. 1995. Use of a free radical method to evaluate antioxidant activity. Lebensm Wiss Technol 28: 25-30.

28. Shin SR, Hong JY, Yoon KY. 2008. Antioxidant properties and total phenolic contents of cherry elaeagnus (Elaeagnus multiflora Thunb.) leaf extracts. Food Sci Biotechnol 17: 608-612.

29. Tsukamoto C, Shimada S, Igita K, Kudou S, Kokubun M, Okubo K, Kitamura K. 1995. Factors affecting isoflavone content in soybean seeds: changes in isoflavones, saponins, and composition of fatty acids at different temperatures during seed development. J Agric Food Chem 43: $1184-1192$

30. Pyo YH, Lee TC, Logendra L, Rosen RT. 2004. Antioxidant activity and phenolic compounds of Swiss chard (Beta vulgris subspecies cycla) extracts. Food Chem 85: 19-26.

31. Lee JH, Baek IY, Ko JM, Kang NS, Shin SH, Lim SG, Oh KW, Shin SO, Park KY, Park KH, Ha TJ. 2008. Antioxidant and tyrosinase inhibitory activities from seed coat of brown soybean. Food Sci Biotechnol 17: 1-7.

32. Marinova EM, Yanishlieva NY. 1997. Antioxidant activity of extracts from selected species of the family Lamiaceae in sun flower oil. Food Chem 58: 245-248.

33. Wong PYY, Kitts DD. 2006. Studies on the dual antioxidant and antibacterial properties of parsley (Petroselinum crispum) and cilantro (Coriandrum sativum) extracts. Food Chem 97: 505-515.

34. Miliauskas G, Venskutonis PR, Van Beek TA. 2004 Screening of radical scavenging activity of some medical and aromatic plant extracts. Food Chem 85: 231-237.

(Received September 7, 2010; Accepted February 22, 2011) 